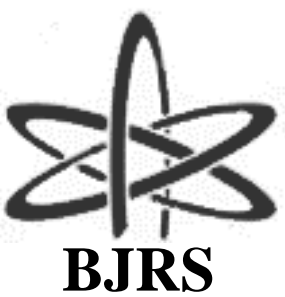
BRAZILIAN JOURNAL
$\mathrm{OF}$
RADIATION SCIENCES
07-02A (2019) 01-09

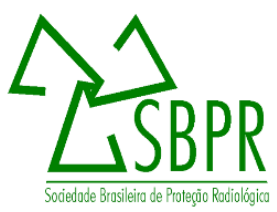

\title{
Protocol for characterization of clay as a backfill and coverage layers for near surface repository
}

\author{
Daisy Mary Marchezini dos Santos ${ }^{1}$, Clédola Cássia Oliveira de Tello ${ }^{1}$ \\ ${ }^{1}$ Centro de Desenvolvimento da Tecnologia Nuclear, 31270-901, Belo Horizonte, MG, Brazil \\ email: marymarchezini@gmail.com
}

\begin{abstract}
The Radioactive Waste Management includes the operations since generation of the waste until its storage in repository, ensuring the protection of human beings and the environment from the possible negative impacts. The radioactive waste is segregated, treated, conditioned in suitable packages for posterior storage or disposal in repository. The "RBMN Project" objective is to implement the repository for the disposal of low and intermediate level radioactive wastes generated by nuclear activities in Brazil, proposing a definitive solution for their storage. Engineered and natural barriers as the backfill and coverage layers will compose the disposal system of a near surface repository, concept proposed by the "RBMN Project". The use of these barriers aims to avoid or restrict the release of radionuclides from the waste to the human beings and environment. The waterproofing barriers are composed of clays. Certainly, for the national repository, will be used those clays existing in the place where it will be constructed. Them some basic tests will have to be carried out to verify the suitability of these clays as barriers. These tests were determined and performed with reference clay, a Brazilian bentonite constituted of $67.2 \%$ montmorillonite. The results were compared with national and international literature of materials with similar mineralogical features. The values found with $95 \%$ of confidence interval were $9.73 \pm 0.35 \mu \mathrm{m}$ for granulometric

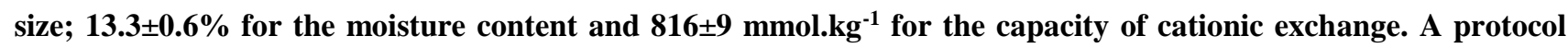
for characterization of clay was elaborated presenting these tests for it future use.
\end{abstract}

Keywords: bentonite, repository, radioactive waste, RBMN Project.

ISSN: 2319-0612

Accepted: 2018-11-02 


\section{INTRODUCTION}

The Comissão Nacional de Energia Nuclear - CNEN - is the Brazilian authority of planning, orientation, supervision and inspection, which establishes standards and regulations in radioprotection and licensing, inspects and controls nuclear activity in Brazil [1]. The nuclear energy in its various applications generates wastes that must be properly treated. For this, there are standards established by CNEN that guide the best way of managing these wastes $[2,3,4,5]$.

According to the Nuclear Safety Glossary [6], radioactive waste or simply waste, is any material resulting from human activities, containing quantities of radionuclide higher than the exemption limits established by CNEN, whose reutilization is not appropriate or foreseen. Also, according to the glossary, final deposit, or repository, is a licensed deposit for storage of radioactive wastes, without the intention of removal, in accordance to the criteria by competent authorities. The radioactive waste are managed to have a form more stable (solid), optimizing and ensure the storage, transportation and final disposal [7].

The International Atomic Energy Agency - IAEA - and CNEN identify the different types of radioactive wastes disposal based on the waste classification [3, 8]. According to CNEN [2], the low and intermediate level radioactive waste belongs to class 2 , in which most of the radioactive waste generated in Brazil is grouped in class 2.1 - low and intermediate level radioactive waste of short half-life - containing beta or gamma emitters, with half-life of approximately 30 years or less. The wastes classified as 2.1 include those generated in the operation of nuclear power plants, in nuclear fuel cycle facilities and from the use of radionuclides in medicine, industry and research, development and innovation activities.

The preferential option to disposal the low and intermediate level radioactive waste of short halflife are near surface installations [9]. The "RBMN Project" is a CNEN priority project aiming the implementation of the repository for the low and intermediate level radioactive waste generated by nuclear energy activities in Brazil, proposing a definitive solution for its storage. The concept proposed by the "RBMN Project" is a repository composed by the deposition area and the support facilities $[10,11]$. Typically, the disposal area is constructed over the ground water level and with low permeability material layers, which has good retention characteristics for the radionuclides present in the waste $[12,13]$. 
These layers must be able enough to retain the release of radionuclides into the environment until their activities decay to a safe level of radiation for humans beings and for the environment. The disposal barriers are composed of the layers under the deposition, the backfill and the concrete structures. In addition, after closing with the concrete barrier, a final coverage is built $[10,14]$. Clays are usually component of the coverage.

The selection the better clay of considers some properties such as low hydraulic conductivity, low diffusion coefficient for radionuclides, high swelling potential, low tendency to segregation and adequate mechanical properties. Among the clays provided for this use is the bentonite, for which a comprehensive study was carried out in the Republic of Korea, using a mixture of calcium bentonite with crushed granite [9]. Another study was the characterization of the bentonite MX 80. That has $65-75 \%$ of montmorillonite $\left((\mathrm{Na}, \mathrm{Ca})_{0,33}(\mathrm{Al}, \mathrm{Mg})_{2} \mathrm{Si}_{4} \mathrm{O}_{10}(\mathrm{OH})_{2} \cdot \mathrm{n}\left(\mathrm{H}_{2} \mathrm{O}\right)\right)$ rich in sodium and it is a reference material for use as engineering barriers [15].

For the national repository, local clays will be used. So some basic tests have to be carried out to verify the suitability of these clays as barriers. As it is not possible to study all the clays, it was developed a protocol, in which the procedures of the basic tests with the reference values are described. For these tests was used a reference clay, a Brazilian bentonite constituted of $67.2 \%$ montmorillonite. The results were compared with national and international literature of materials with similar mineralogical features.

\section{MATERIALS AND METHODS}

The material used as reference for the protocol was an activated sodium bentonite constituted of 67.2\% montmorillonite, available in Brazilian territory [16]. The tests for the characterization were: granulometric determination, moisture content, cation exchange capacity and compaction curve. The test procedures were organized in the Characterization Protocol. The Figure 1 summarizes the methodology used to establish this Protocol. 
Figure 1: Flowchart of the methodology used to elaborate the Protocol

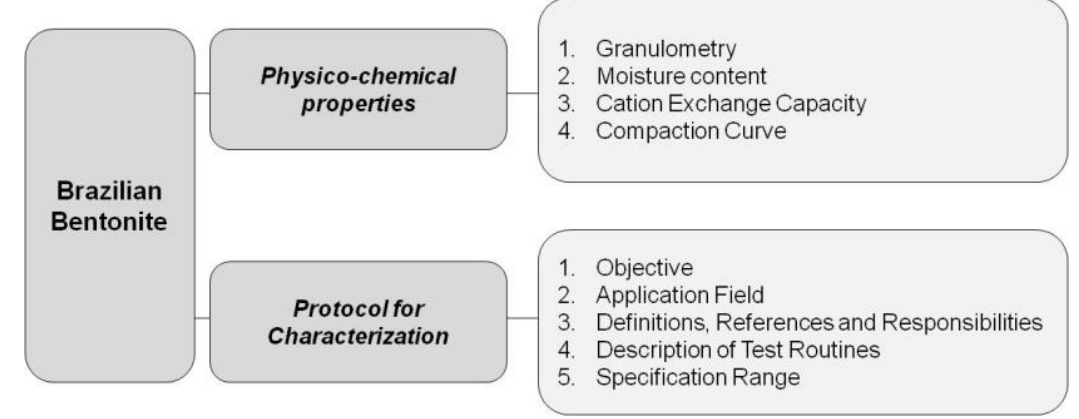

The characterization tests available in the protocol were carried out in triplicate. For the statistical treatment of data, significance tests were made using the Student Distribution for a sample with a 95\% confidence interval corresponding to the mean of the results. Minitab® software was used [10].

\subsection{Granulometry Test}

Three granulometric distribution tests were carried: sieve test, elutriation test and laser diffraction test. The most efficient method for the granulometric determination of the reference material was the laser diffraction. The granulometric classification method by sieving is a low cost and efficient test for particles with a mean diameter of $75 \mu \mathrm{m}$. The classification by the elutriation method is restricted to the standard diameter of each cyclone, ranging from $12.8 \pm 0.5$ to $43.8 \pm 1.0 \mu \mathrm{m}$ [10].

The granulometric distribution by laser diffraction was obtained using the Cilas 1190 Liquid equipment of the Nuclear Fuel Laboratory - LABCOM/SENAN/CDTN.

In the granulometric distribution by laser diffraction the sample was dispersed in water. Then the sample was attained by a laser beam, which generated the results of the particle distribution of the material. Data were calculated by the equipment software and the graphs were generated automatically [10]

\subsection{Moisture Content}


To determine the moisture content the total amount of the bentonite was divided in four equal portions and from these ones, two opposite parts were mixed to obtain a new sample and the other ones were discarded. The same procedure was repeated until a $20 \mathrm{~g}$-sample was obtained. The method described in CDTN-RT-417 [17] was used to determine the clay moisture. The sample of bentonite was dried (temperature about $105^{\circ} \mathrm{C}$ ) until it reached a constant mass. The difference between the weight of the sample before and after drying is equivalent to the mass of water [18].

\subsection{Cation Exchange Capacity Determination}

The cation exchange capacity (CEC) was determined by the methylene blue (MB) adsorption method described by Freire et al. [19, 20]. Approximately $2 \mathrm{~g}$ of bentonite were dispersed in $300 \mathrm{~mL}$ of water, so that slurry is produced. The $\mathrm{pH}$ of this slurry was adjusted with sulfuric acid in order to remain in the range from 2.5 to 3.8. Then this slurry, under stirring, was titrated with methylene blue solution (0.1 mol. $\left.\mathrm{L}^{-1}\right)$ adding 1-mL increments. After each increment of MB solution, a drop of the slurry was put on the filter paper to verify the end point, which is indicated by the formation of a light blue halo around the drop (Figure 2). The used MB volume was registered to calculate the CEC, in accordance of Equation 1.

$$
C E C=C_{A M} x V_{A M} x \frac{1000}{m_{a}}
$$

Where, $\mathrm{CEC}=$ cation exchange capacity $\left(\operatorname{mol}_{\mathrm{c}} \cdot \mathrm{kg}^{-1}\right) ; \mathrm{C}_{\mathrm{AM}}=$ concentration of methylene blue $\left(\right.$ mol. $\left.\mathrm{L}^{-1}\right) ; \mathrm{V}_{\mathrm{AM}}=$ spent volume of the methylene blue $(\mathrm{L}) ; \mathrm{m}_{\mathrm{a}}=$ mass of the dry sample $(\mathrm{g})$. 
Figure 2: Appearance of the drop in the adsorption process of methylene blue

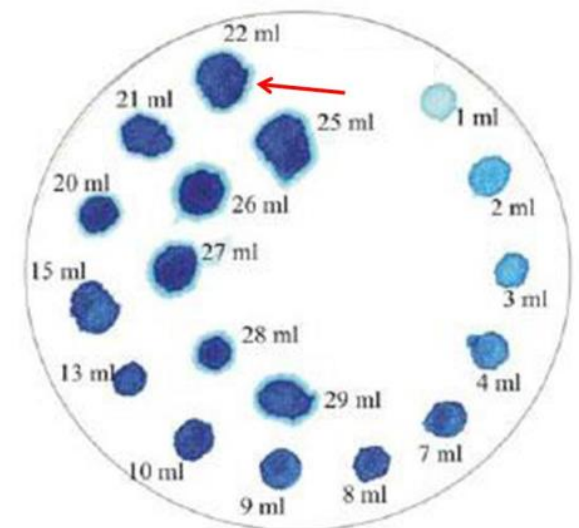

Source: adapted Santos (2006) [21]

\subsection{Compactation Curve}

The compaction curve is the graphical relationship of the dry density to moisture content of the material. From the compaction curve it is possible to determine its optimum moisture. The data for the curve were obtained by several compactions of the bentonite with different moistures - 20, 25 , 30,35 e $40 \%$ - into the Standard Proctor cylinder [22, 23]. The optimum moisture is a value that corresponds to the point of maximum dry density on the compaction curve [24].

To determine the dry apparent specific gravity value (Yd) (Equation 2) was calculated the weight of moist bentonite $(\mathrm{Ph})$ (Equation 3) and the its natural weight (YNAT) (Equation 4) [10].

$$
\begin{gathered}
Y_{d}=\frac{Y_{N A T}}{1+w} \\
P_{h}=P_{B R}-P_{C I L} \\
Y_{N A T}=\frac{P_{h}}{V_{T}}
\end{gathered}
$$


Where, $w=$ moisture content $(\%) ; P_{C I L}=$ weight of the cylinder proctor empty $(\mathrm{g}) ; P_{B R}=$ absolute weight of the system (cylinder and sample) $(\mathrm{g}) ; V_{T}=$ volume of the compacted bentonite $\left(\mathrm{cm}^{3}\right)$.

The compaction curve generates the polynomial regression equation, from which the values of optimum moisture (Equation 5) and the apparent dry maximum weight (Equation 6) were calculated [10]. The Yd values were plotted with the moisture content, and from there, the polynomial regression equation was established.

$$
\begin{gathered}
\text { Optimum }_{\text {moisture }}=-\frac{b}{2 a} \\
Y_{d m a ́ x}=-\frac{b^{2}-4 a c}{4 a}
\end{gathered}
$$

\section{RESULTS AND DISCUSSION}

\subsection{Granulometric Distribution}

The Table 1 shown the mean values of particle diameter that were obtained in the laser diffraction test. It is observed in the literature that the mean sizes of particles for the clays are less that 0.5 $\mathrm{mm}$, different than was obtained. 
Table 1: Mean values of particle diameter of the bentonite.

\begin{tabular}{|c|c|c|c|}
\hline \multirow[t]{2}{*}{ Test } & \multirow{2}{*}{ Replicate } & \multicolumn{2}{|c|}{$\begin{array}{l}\text { Mean value of diameter } \\
\qquad(\mu \mathrm{m})\end{array}$} \\
\hline & & By replicate & By test \\
\hline \multirow{3}{*}{$\mathrm{T} 1$} & 1 & 10.15 & \multirow{3}{*}{9.85} \\
\hline & 2 & 9.83 & \\
\hline & 3 & 9.58 & \\
\hline \multirow{3}{*}{$\mathrm{T} 2$} & 1 & 9.50 & \multirow{3}{*}{9.57} \\
\hline & 2 & 9.64 & \\
\hline & 3 & 9.57 & \\
\hline \multirow{3}{*}{$\mathrm{T} 3$} & 1 & 9.50 & \multirow{3}{*}{9.76} \\
\hline & 2 & 9.93 & \\
\hline & 3 & 9.84 & \\
\hline
\end{tabular}

This may be due to the method used for this measurement, in which the clay dispersed in water may generate lumps with larger diameters than the totally dry grains. For the present study this is not an exclusion parameter of the material for use as natural barriers in surface repositories.

\subsection{Bentonite Moisture Content}

The values for the moisture content varied between 13.0 and $13.4 \%$ and the mean of the three replicates was $13.3 \%$.

\subsection{Cation Exchange Capacity (CEC) of the Bentonite}

The Table 2 shown the results of the CEC tests. 
Table 2: Results of the CEC by methylene blue (MB) adsorption test.

\begin{tabular}{cccccc}
\hline Test & $\begin{array}{c}\text { Mass } \\
(\mathbf{g})\end{array}$ & $\begin{array}{c}\text { Slurry initial } \\
\mathbf{p H}\end{array}$ & $\begin{array}{c}\text { Adjusted } \\
\mathbf{p H}\end{array}$ & $\begin{array}{c}\text { Volume of MB } \\
(\mathbf{L})\end{array}$ & $\begin{array}{c}\text { CEC } \\
\left(\mathbf{m m o l . k g}^{-1}\right)\end{array}$ \\
\hline CEC 1 & 2.08 & 10.20 & 3.74 & 0.169 & 813 \\
\hline CEC 2 & 2.06 & 10.38 & 3.76 & 0.169 & 820 \\
\hline CEC 3 & 2.10 & 10.26 & 3.75 & 0.171 & 814 \\
\hline
\end{tabular}

\subsection{Compaction Curve of the Bentonite}

For compaction curve was used the Origin ${ }^{\circledR}$ software and it is represented in the Figure 3 with its respective the polynomial regression equation. From of the coefficients of the polynomial regression and using Equations 5 and 6, the values for optimum moisture and for the maximum specific dry weight were obtained, and they are $32.4 \%$ and $0.878 \mathrm{~g} . \mathrm{cm}^{-3}$, respectively.

Figure 3: Compaction curve of the bentonite

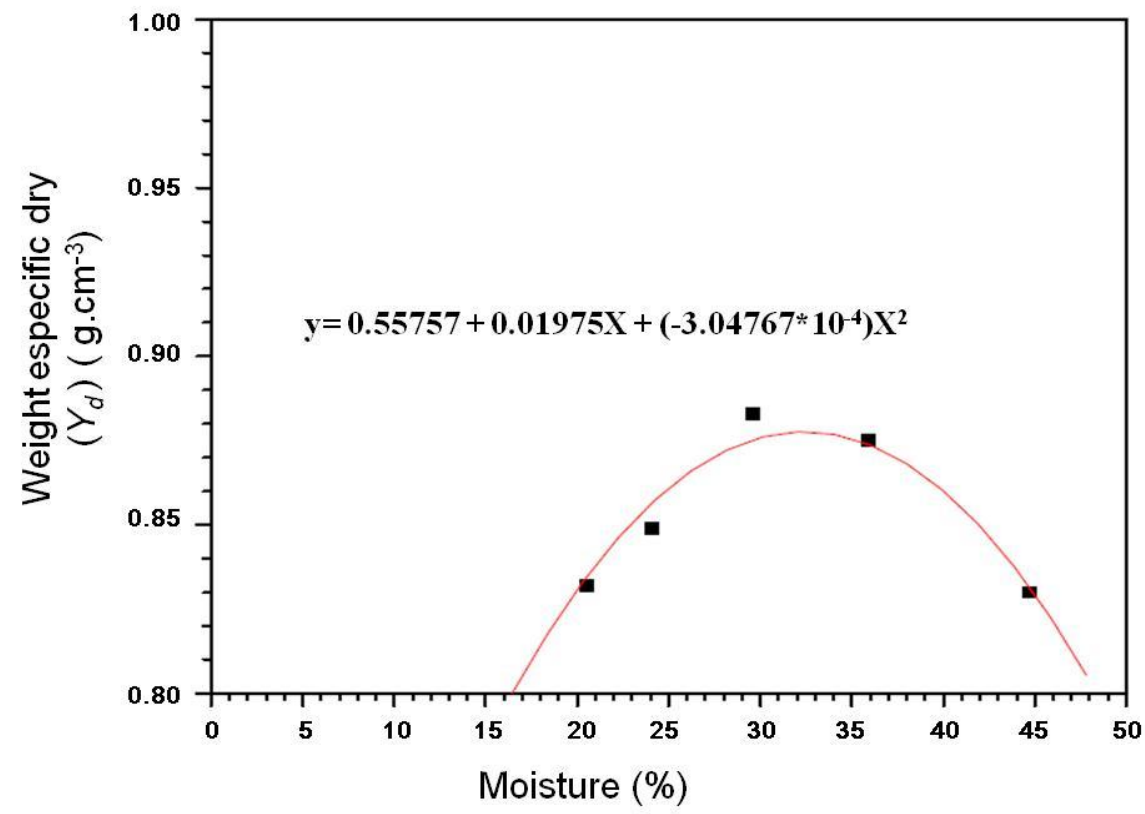




\subsection{The specification range}

The Figure 4 shown the graphic with the specifications range established for the Protocol with a $95 \%$ confidence interval. The values found were $9.73 \pm 0.35 \mu \mathrm{m}$ for granulometric size; $13.3 \pm 0.6 \%$ for the moisture content and $816 \pm 9$ mmol. $\mathrm{kg}^{-1}$ for the capacity of cationic exchange.

Figure 4: Specification range for the: (a) Granulometric Determination by the laser diffraction test; (b) bentonite moisture content; (c) CEC test by adsorption of $M B$
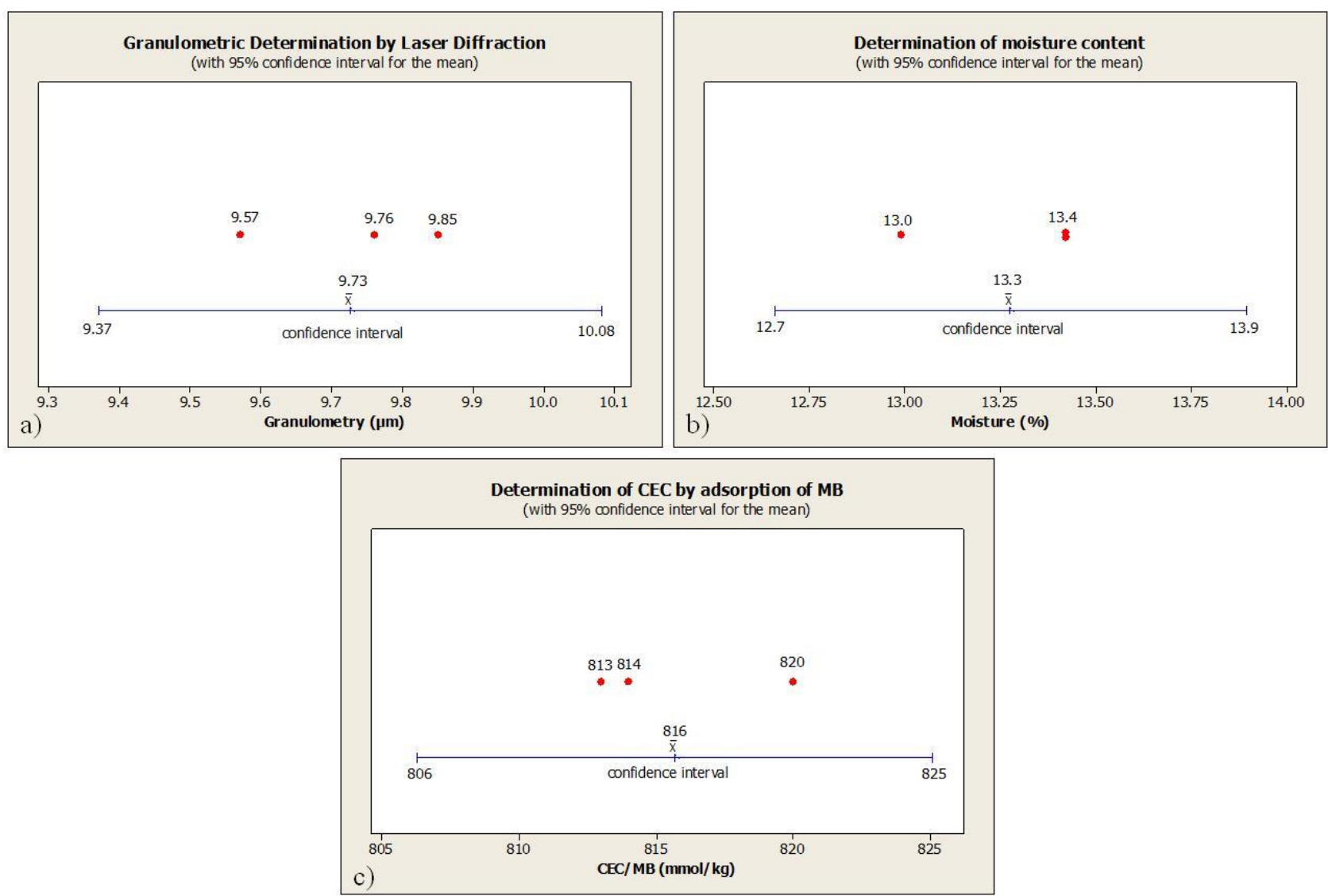

\subsection{Characterization Protocol}

For the characterization protocol was elaborated aiming at the physical-chemical characterization process of clays to be used as a backfill and coverage layer for surface repository. This protocol was included in the internal operational procedures of the LABCIM/CDTN and is available. 
The Figure 5 shown the possibilities to use the protocol. The results from other materials should be compared with the reference values of the protocol and after this comparison a technical and economical analysis will be performed to use one of these options.

Figure 5: Schematic for the use of the protocol

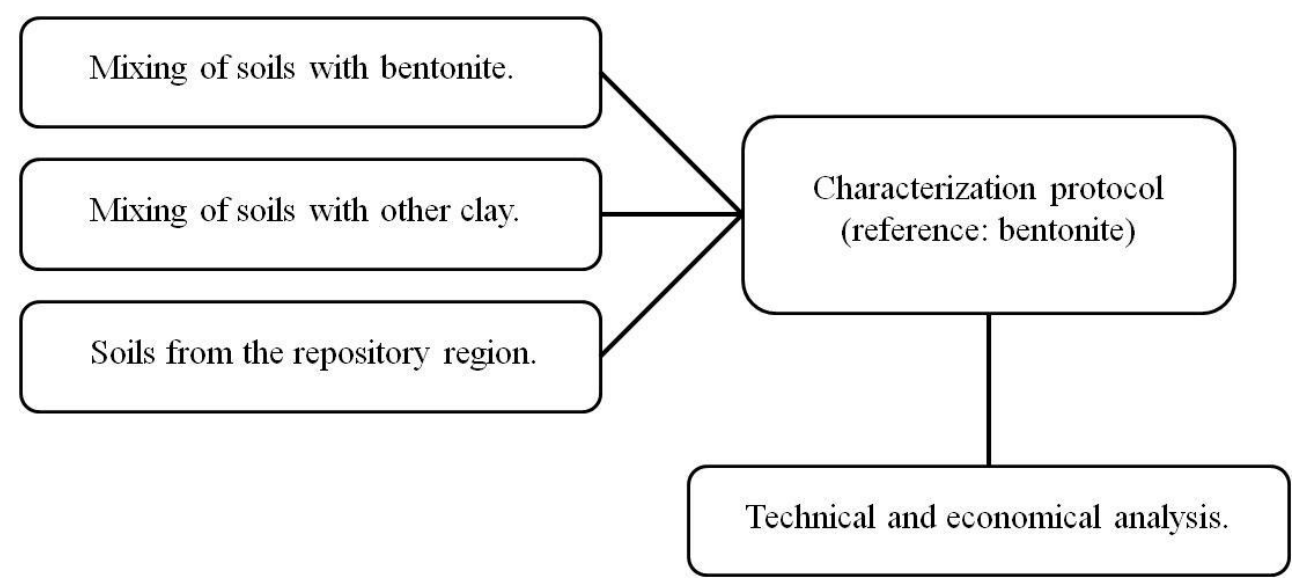

\section{CONCLUSION}

Once the physical-chemical tests were developed with the reference material, a characterization protocol was developed that will allow other materials to be characterized for use as barriers in a surface repository, since it has a set of basic data for this purpose. Other tests should be included in the protocol in order to improve the initial characterization. It is suggested a protocol validation study using other soils and mixtures with the reference material. In addition, a modeling study of the transport of contaminants by diffusion through clay barriers is being developed in the CDTN. 


\section{ACKNOWLEDGMENT}

This research project is supported by Nuclear Technology Development Center (CDTN) and by the funding source Brazilian Nuclear Energy Commission (CNEN). I thank to technical team of the CDTN by the support in performing of the tests.

\section{REFERENCES}

[1] CNEN - Comissão Nacional de Energia Nuclear. Quem somos. Rio de Janeiro, Brazil, 2015. Available at: <http://www.cnen.gov.br/quem-somos>. Last accessed 30 Nov. 2017

[2] CNEN - Comissão Nacional de Energia Nuclear. Gerência de Rejeitos Radioativos de Baixo e Médio Níveis de Radiação. CNEN-NN-8.01, Resolução 167/14, Rio de Janeiro: CNEN, 2014. $45 \mathrm{p}$.

[3] CNEN - Comissão Nacional de Energia Nuclear. Licenciamento de Depósitos de Rejeitos Radioativos de Baixo e Médio Níveis de Radiação. CNEN-NN-8.02, Resolução 168/14, Rio de Janeiro: CNEN, 2014. 32p

[4] CNEN - Comissão Nacional de Energia Nuclear. Seleção e escolha de locais para depósitos de rejeitos radioativos. CNEN-NE-6.06, Resolução 014/89. Rio de Janeiro: CNEN, 1990. 14p

[5] CNEN - Comissão Nacional de Energia Nuclear. Critérios de aceitação para deposição de rejeitos radioativos de baixo e médio níveis de radiação. CNEN-NN-6.09, Resolução 012/02. Rio de Janeiro: CNEN, 2002. 11p

[6] CNEN - Comissão Nacional de Energia Nuclear. Nuclear Safety Glossary. Rio de Janeiro: CNEN, 2012.60p.

[7] IAEA - International Atomic Energy Agency. Disposal of radioactive waste. IAEA SSR-5, Vienna: IAEA, 2011. 83p.

[8] IAEA - International Atomic Energy Agency. Classification of radioactive waste. IAEA GSG1, Vienna: IAEA, 2009. 68p. 
[9] IAEA - International Atomic Energy Agency. Performance of engineered barrier materials in near surface disposal facilities for radioactive waste. IAEA TECDOC-1255, Vienna: IAEA, 2001. 56p.

[10] SANTOS, D. M. M., 2017 Elaboração de protocolo para caracterização de argilas como material de recheio e de cobertura para repositório de superfície. MSc Thesis. Centro de Desenvolvimento da Tecnologia Nuclear, Belo Horizonte, Brazil. 111p.

[11] TELLO, C. C. O. Status of the Implementation of Brazilian National Repository, In: INTERNATIONAL NUCLEAR ATLANTIC CONFERENCE, 2015, São Paulo. Annals... São Paulo: Comissão Nacional de Energia Nuclear, 2015.

[12] IAEA- International Atomic Energy Agency. Upgrading of near surface repositories for radioactive waste. IAEA Technical reports No. 433, Vienna: IAEA, 2005. 147p.

[13] OECD - Organisation for Economic Co-Operation and Development/Nuclear Energy Agency. Low-Level Radioactive Waste Repositories: An Analysis of Costs. Paris, France: OECD. 1999. Available at:<http://www.oecd-ilibrary.org/nuclear-energy/low-level-radioactivewaste-repositories_9789264172029-en>. Last accessed 30 Nov. 2017.

[14] TELLO, C.C.O. Efetividades das Bentonitas na retenção de césio em produtos de Rejeitos Cimentados. DSc Thesis. Faculdade de Engenharia Química, Campinas: UNICAMP, 2001. 167p.

[15] IAEA - International Atomic Energy Agency. Characterization of swelling clays as components of the engineered barrier system for geological repositories. IAEA TECDOC1718, Vienna: IAEA, 2013. 118p.

[16] DNPM - Departamento Nacional de Produção Mineral. Sumário Mineral 2015, Brasília: DNPM, 2016. Available at: <http://www.dnpm.gov.br/dnpm/sumarios/sumario-mineral2015/view>. Last accessed: 30 Nov 2017.

[17] SILVA, T. V.; HAUCZ, M. J. A. Determinação do teor de umidade em argilas. RT LABCIM - SEGRE/CDTN-0417, Belo Horizonte: LABCIM-CDTN, 2005. 5p.

[18] SANTOS, D. M. M., TELlO, C. C. O. Establishment Of Characterizing Parameters Of Clay As A Filling Material And Coverage For Repository, In: INTERNATIONAL NUCLEAR ATlantiC CONFERENCE, 2015, São Paulo. Annals... São Paulo: Comissão Nacional de Energia Nuclear, 2015. 
[19] FREIRE, C. B.; HAUCZ, M. J. A.; TELLO, C. C. O. Determinação da capacidade de troca catiônica (CTC) de argilas utilizando o método da adsorção de azul de metileno (AAM). NI LABCIM - SEGRE/CDTN, Belo Horizonte: LABCIM-CDTN, 2012. 7p.

[20] ASTM - American Society for Testing and Materials. Standard Test Method for Methylene Blue Index of Clay. C837-14. 2014. p. 01-02.

[21] SANTOS, L. V.; POlivanOV, H.; AlaminO, R. C. J.; SILVA, V. H. G. Adsorção de Cloreto e Potássio em Solos Tropicais. Rio de Janeiro, Brazil. 2006. Available at: < http://www.ppegeo.igc.usp.br/index.php/anigeo/article/view/4871>. Last accessed: 30 Nov. 2017.

[22] PINTO, C. S. Curso Básico de Mecânica dos Solos. $3^{\text {rd }}$ Ed. São Paulo: Oficina de Textos, 2006.

[23] ASTM - American Society for Testing and Materials. Standard Test Methods for Laboratory Compaction Characteristics of Soil Using Modified Effort $\left(56,000\right.$ ft-lbf/ft ${ }^{3}$ (2,700 kN-m/m³)). D1557-12. 2012. p.01-14.

[24] ABNT - Associação Brasileira de Normas Técnicas. Solo: Ensaio de compactação. NBR 7182. 1986. p.1-10. 